\title{
Piping layout for fire sprinkler system: An overview
}

\author{
Kshitiz Vishnoi
}

\begin{abstract}
In today's times, the designing of piping systems has become an important field. With increased urbanization, and construction of complex infrastructures like advanced warehouses, factories, power distribution centers, refineries, multi-storied residential and commercial buildings, etc. , having a good piping system is a must for supplying adequate amount of clean water for fighting against fire threats. Earlier, piping design was done by using many manual calculations and formulation methods. This made piping design a laborious and time-consuming process and it was also prone to large amount of errors. However, modern piping design is done by using software such as ANSYS, CFD, AUTOCAD, etc. for doing calculations and drawing/designing the required layout. This not only reduces the computation times, but also allows us to have a virtual simulation of the chosen design, thereby giving us a better idea about how effective the chosen piping design will be before it is implemented, thus allowing us to fine tune the design for better output and also reducing the errors. In this paper, we highlight the requirements of a good piping system, and we elaborate upon the various steps involved in designing of such systems, and choosing the suitable type of piping layout for the required conditions such as available pressure, consumption demand, flow rate, etc. and performing various calculations on the basis of the above factors.
\end{abstract}

Index Terms - Fire protection, Piping layout, Sprinkler system, System Design.

\section{INTRODUCTION}

Piping Network is a system of pipes and trenches which provide the appropriate quality and quantity of water to a community. The design, construction and layout of the piping network have to be carefully prepared in order to ensure that there is enough flow pressure to supply hygienically safe water. Once the network is constructed, its maintenance has to be performed, which includes repairs, leakage control, prevention of recontamination, etc. Along with maintenance, the proper operation of pumping stations has to be ensured for areas where gravity pressure alone is not enough (Figure 1).

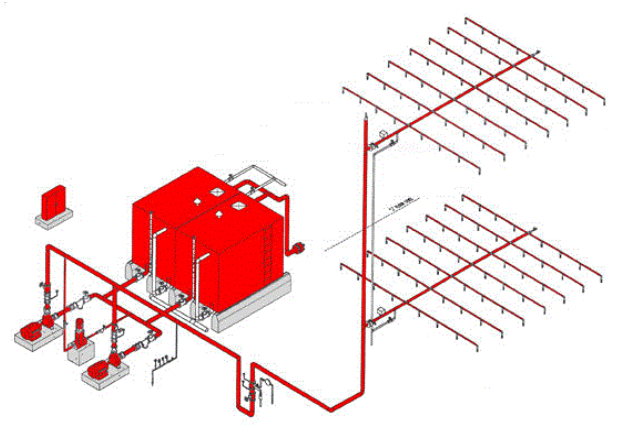

Figure-1: Model showing sprinkler network

Kshitiz Vishnoi, Design Department, EAST Corp, Mumbai, INDIA, +919869193090.

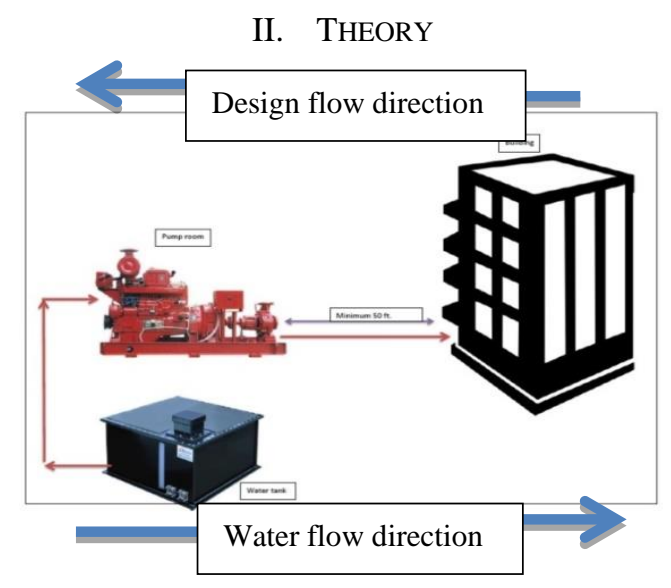

Figure-2: System design vs water flow direction

Requirements of an Adequate Distribution System:

For an adequate water distribution system, the requirements are as follows:

1. Water quality should not deteriorate while flowing through the distribution pipes.

2. The system should be capable of supplying water to all the intended places with sufficient pressure head.

3. It should be capable of supplying the required amount of water during firefighting.

4. The layout should be such that no consumer is without water supply, during the repair of any section of the system.

6. It should be fairly watertight to minimize losses due to leakage.

The design of water distribution for firefighting (Figure 2) consists of the following main steps:

1. Preliminary Studies

2. Design Phases

3. Network Layout

4. Hydraulic Analysis

1. Preliminary Studies: - This is the first and the most important step in the designing of water distribution system. Before any design work can commence, thorough observations and studies have to be carried out Preliminary studies consist of the following sub-steps:

a. Topographical studies must be performed before starting the actual design work.

b. Digital maps showing present (and future) houses, streets, lots, and so on should be made.

c. Location of water sources and pumping stations should be considered so that distribution reservoirs can be easily located.

- Water Demand Studies: Studies have to be made on the amount of water that is required to a particular area on the basis of the fire demand, the population and the area of the structure/land under 
consideration. This can be determined by the following formulae:

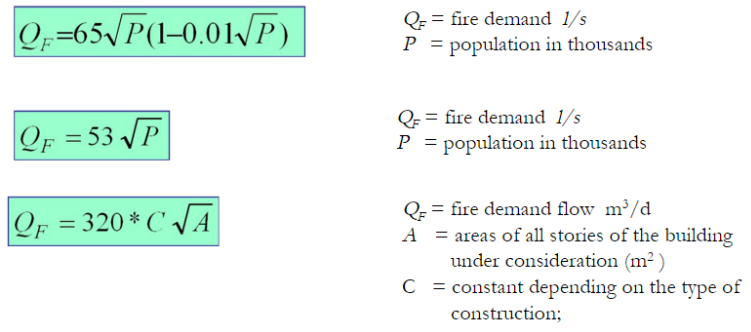

(Fire demand formulae)

2. Design Phases: - After the preliminary studies are performed, the next step is setting the Design Criteria. This step involves setting the required design limitations/parameters that are required to get the most effective and economical water-distribution in the chosen network. The required limitations/parameters can determined on the basis of the following factors:

a. Hazards classification: System depends not only on the size of the risk but also on its fire growth and spread potentialities, the risk are to be categorized under following classes (Figure 3) for the purpose of system design.

a) Light hazard

b) Ordinary hazard-1

c) Ordinary hazard-2

d) Extra-ordinary hazard-1

e) Extra-ordinary hazard-2

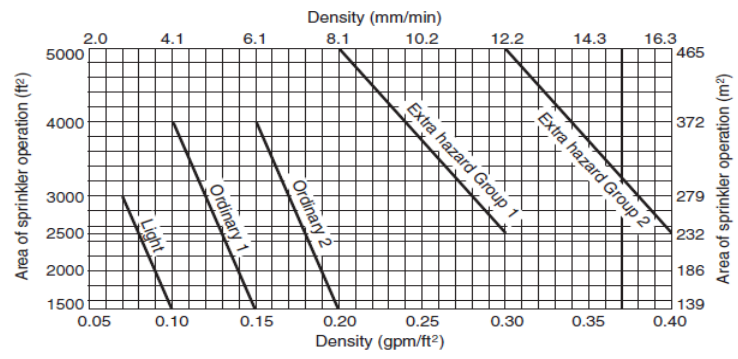

Figure- 3 : Density/Area curve (NFPA - 13 chapter 3 clause $-3.3 .15)$

b. Demand: Demand is the quantity of water required to flow from a fire sprinkler. Mathematically, Demand (Quantity) = Area X Density

The area of sprinkler head (coverage) and the required design density can be chosen from figure 3 as per the hazard classification.

Therefore if we have ordinary-1 hazard, area = $186 \mathrm{~m}^{2} \&$ density $=5.9 \mathrm{~mm} / \mathrm{min}$ ( from figure 3 )

Demand $=$ Area $\mathrm{X}$ Density

Demand $=186 \times 6.1$

Demand $=1134.6 \mathrm{l} / \mathrm{m}$

This would be the minimum flow rate required for the sprinkler head to prove the correct design density.

c. K-Factor: K-factors are known as the coefficient of discharge. The larger the $\mathrm{K}$ factor in number, the more water it can discharge at a given pressure.

d. Pressure: Pressure is an expression of force exerted on a surface per unit area. A fire pipe carrying water is always under pressure. As per codes, it is mandatory to have a minimum pressure of 0.5 bars at the remotest nozzle for the operation with the water hammering and cooling effect.

e. Flow: The flow rate or the discharge from a sprinkler head or water mist nozzle can be calculated from the formula below:

$$
\text { Flow }(q)=k \sqrt{ } P
$$

Where $\mathrm{k}$ is the $\mathrm{K}$-factor

$$
\mathrm{P} \text { is the pressure }
$$

Assuming K-factor $=80$ and pressure $=0.5$

Therefore, Flow $=80 \sqrt{ } 0.5$

Flow $(q)=56.5681 / \mathrm{m}$

This is minimum flow required for the system.

f. Pipe size: Water pipe sizing procedures are based on a system of pressure requirements and losses (Figure 4), the sum of which must not exceed the minimum pressure available at the supply source.

The required pipe size is chosen to maintain the flow/cost effectiveness (Figure 5).

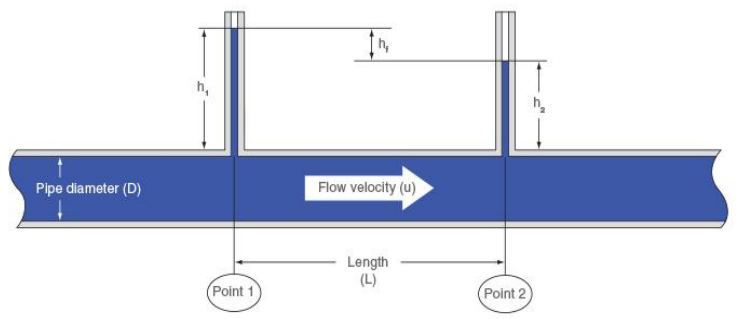

Figure-4: Friction loss in pipes due to the flow

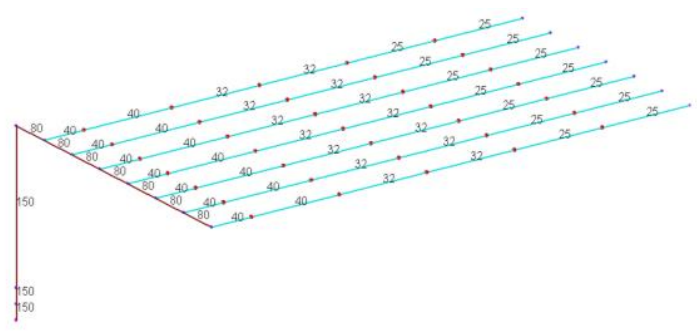

Figure-5: Pipe sizing with pipe schedule method

g. Velocity: The equilibrium speed of flow of water in the pipe shall not exceed $6 \mathrm{~m} / \mathrm{s}$ at any valve or flow monitoring device, or $10 \mathrm{~m} / \mathrm{s}$ at any other point in the system for the stabilized flow condition at the demand point involving an AMAO.

h. Head loss: Head loss cannot be prevented but can be minimised. Head loss is due to water flow against gravity, pipe fittings (T-joints, Elbows, and Couplings), Valves (Butterfly valve, Gate Valves) and friction losses (major \& minor loss) in the pipes.

i. Avg. water consumption: According to the average water consumption, the capacity of water storage tank (per hour basis) has to be defined. This depends upon the potential hazard that could be encountered:
a. Light hazard ------- 30 mins.
b. Ordinary hazard --------- 60 mins to 90 mins
c. Extra-ordinary hazard ---------- 90 to $120 \mathrm{mins}$

j. Spacing between 2 sprinklers: This depends on the coverage area of the sprinkler. Spacing is generally 
kept between 3 mtrs to 4 mtrs. There are mainly two types of spacing provided as per the design criteria as shown in figure 6 . They are - Triangular spacing and Rectangular spacing.

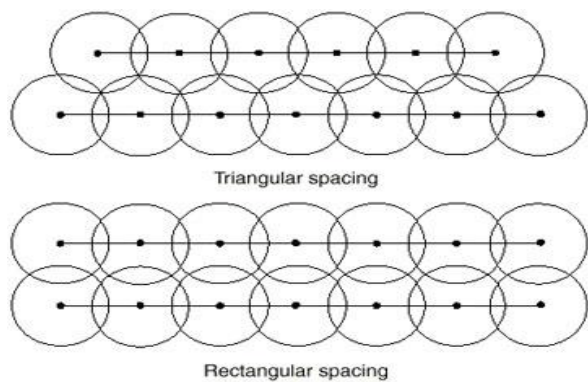

Figure-6 : Spacing between sprinklers w.r.t. coverage

k.Selection of material: Pipes that are mainly used in fire industries is -40 galvanised steel. But as per NFPA and IS codes CPVC piping can also be used (only for light hazards)

1. Codes to be followed - There are many codes/regulations that can be followed for designing the fire protection system. For example NFPA, FM, OSID, BIS, NBC, TAC or any other local codes.

3. Network Layout: - After the design criteria are determined, the next step is to choose a suitable pipe network layout and to estimate pipe sizes on the basis of water demand and local code requirements. The pipes are then drawn on a digital map (using AutoCAD, for example), starting from the water source (Figure 7). All the components i.e. pipes, valves, fire hydrants, etc. of the water network should be shown on the lines. These layouts are used by project executers (contractors) for implementation (installation).

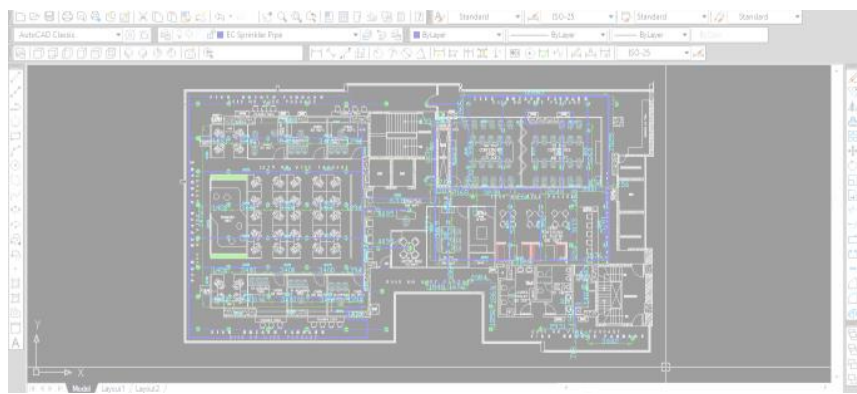

Figure-7: A screen-shot of piping in AutoCAD layout

\section{ANALYSIS AND DISCUSSION}

There are 3 types of piping layouts possible in fire protection $\bullet$ designing. They are:

A. Branching pattern with dead end. (Tree system)

B. Grid pattern (Gridiron system)

C. Grid pattern with loop. (Circular or ring system)

\section{A. Branching Pattern with Dead End}

This is the simplest type of piping layout. It is called a Branching pattern as it looks similar to the branching of a tree (Figure 8).
It consists of the following components:

- Reservoir.

- Main (trunk) line

- Sub-mains

- Branches.

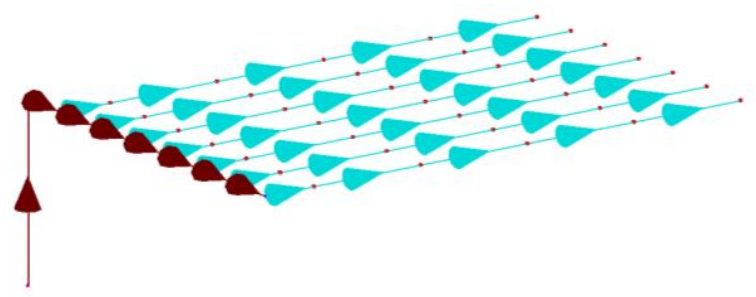

Figure-8 : Water flow in Tree-system

Main line is the main source of water supply. There is no direct supply from the main trunk line, the water is first supplied to the consumers from the main line through the sub-mains, which are connected to the main line and they are laid along the main roads. From the sub-mains, the water then flows through the branches which are connected to the sub-mains and they are laid along the streets. From the branches, the water lastly flows through the service connections which are connected to the branches and thus the water is supplied to the consumers.

\section{Advantages:}

- It is a very simple layout for water distribution. Design calculations are easy and simple to do.

- The required dimensions of the pipes for this layout are small, thus it is economical and cheap.

- This layout requires comparatively less number of cut-off valves.

However, this layout is not usually favoured in modern water works practice due to the following disadvantages.

\section{Disadvantages:}

- The area receiving water from a pipe under repair is without water until the work is completed.

- In this system, there are large numbers of dead ends where water does not circulate but remains static. Sediments accumulate due to stagnation of water at these dead ends and bacterial growth may occur at these points. To overcome this problem, drain valves are provided at dead ends and stagnant water is drained out by periodically opening these valves but a large amount of water is wasted.

- It is difficult to maintain chlorine residues at the dead ends of the pipe.

- Water available for fire-fighting will be limited since it is being supplied by only one water main.

The pressure at the end of the line may become undesirably low as additional areas are connected to the water supply system. This problem is common in many lesser-developed countries, where this type of piping layout is common. 


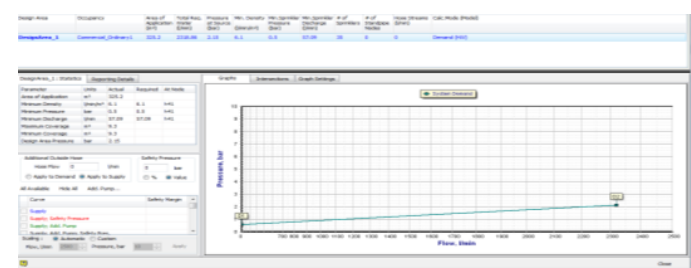

Figure-9 : Software generated report for tree system (screen-shot)

\section{B. Grid Pattern}

In grid pattern type layout, all the pipes are interconnected with no dead-ends (Figure 10). In such a system, water can reach any point from more than one direction. This system cannot be designed with pipe schedule method. It has to be done with hydraulically designed method.

It consists of the following components:

- Reservoir

- Main line

- Branches.

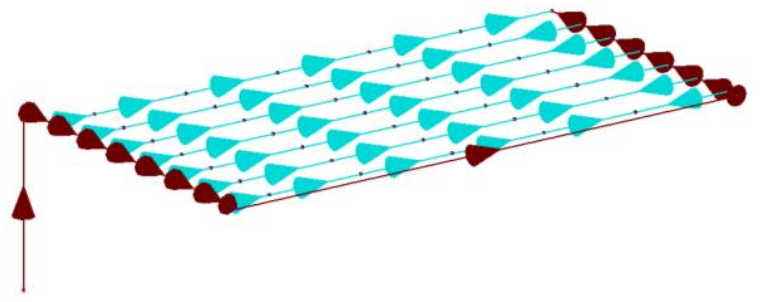

Figure-10: Water flow in Grid system

\section{Advantages:}

- Since water in the supply system is free to flow in more than one direction, stagnation does not occur as readily as in the branching pattern piping layout.

- In case of repair or break down in a pipe, the area connected to that pipe will continue to receive water, as water will flow to that area from the other side.

- Water reaches all points with minimum head loss.

- At the time of fires, by manipulating the cut-off valves, plenty of supplied water can be diverted and be used for concentrated fire-fighting.

\section{Disadvantages:}

- Cost of laying the pipes is more because relatively longer pipes are required.

- More number of valves are required. The calculations of pipe sizes are more complicated.

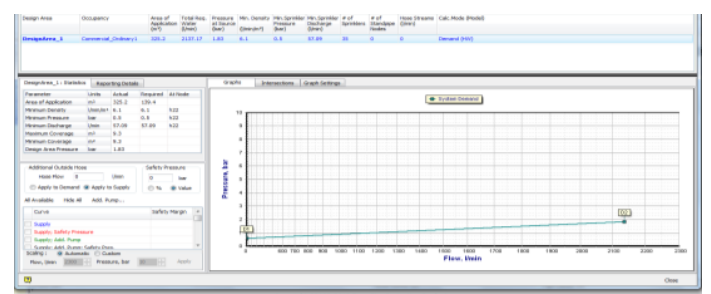

Figure-11: Software generated report for Grid system (screen-shot)

\section{Grid Pattern with Loops:}

This type of pipe layout is a modified type of Grid pattern layout (Figure 12). In this layout, loops are provided in a grid pattern to improve water pressure in certain portions of a city (industrial, business and commercial areas). The loops should be strategically located so that as the city develops, the required water pressure should be sustained. It consists of the following components:

- Reservoir

- Main line

- Branches.

The advantages and disadvantages of this pattern are the same as those of the grid pattern.

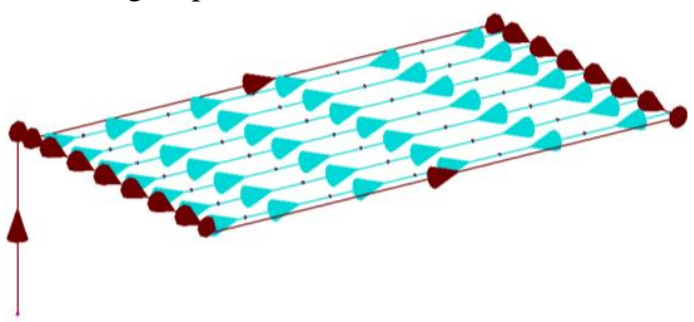

Figure-12 : Water flow in Loop system

\section{Advantages:}

- Since water in the supply system is free to flow in more than one direction, stagnation does not occur as readily as in the branching pattern.

- This system is balanced as water reaches all points with minimum time and minimum head loss.

- At the time of fires, by manipulating the cut-off valves, plenty of supplied water can be diverted and be used for concentrated fire-fighting.

- Designing of the system is much easier than grid system.

\section{Disadvantages:}

- Cost of laying the pipes is more because relatively longer pipes are required as in tree and grid system.

- More number of valves are required to isolate.

- This system cannot be designed with pipe schedule method. It has to be hydraulically designed.

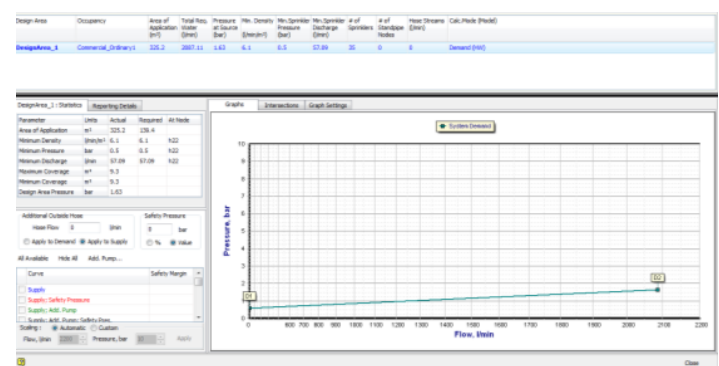

Figure-13: Software generated report for loop system (screen-shot)

4. Hydraulic Analysis (Of Distribution Systems):After the suitable type of pipe layout is chosen, the next and final step involves the analysis of the chosen layout. This involves calculating the flow rate, supplied water pressure, volume, losses, etc. The calculation process is done using hydraulic analysis software like SprinkCALC, PipeNET, SprinkCODE etc. These softwares are designed especially for calculations of piping for fire protection systems. 


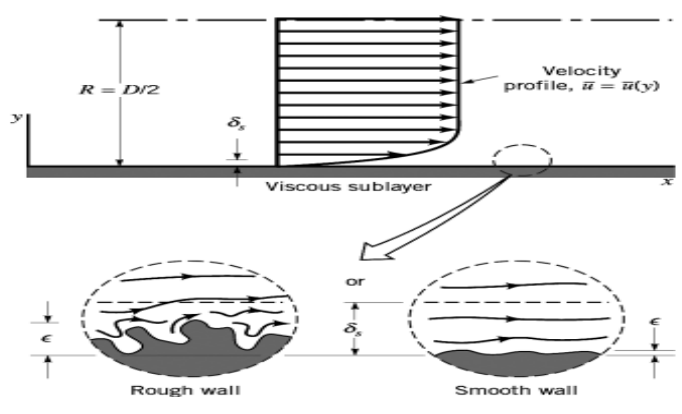

Figure-14: Friction losses in pipes.

\section{Friction Losses in Pipes}

Friction losses are a complex function of the system geometry, the fluid properties and the flow rate in the system. By observation, the head loss is roughly proportional to the square (Figure 14) of the flow rate in most engineering flows (fully developed, turbulent pipe flow). This observation leads to the Hazen-Williams equation for head loss due to friction:

$$
V=k C R^{0.63} S^{0.54}
$$

where:

- $\quad V$ is velocity

- $\quad k$ is a conversion factor for the unit system $(\mathrm{k}=1.318$ for US customary units, $\mathrm{k}=0.849$ for SI units)

- $C$ is a roughness coefficient

- $R$ is the hydraulic radius

- $\quad S$ is the slope of the energy line (head loss per length of pipe or $h_{f} / L$

\section{RESULT}

On comparing all the three possible piping layouts, keeping few parameters constants, the following result is obtained through hydraulic analysis using SprinkCALC software.
$\mathrm{K}=80.3$
Coverage $=9.3 \mathrm{~m}^{2}$
Total no. of sprinklers operated $=35$
Calculation Mode - Demand
Hydraulic Model - Hazen-Williams
Fluid Name - Water @ 60F (15.6C)
Min. Density $\left(1 / \mathrm{min} / \mathrm{m}^{2}\right)-6.1$
Type of System - wet

\section{Result Table:}

\begin{tabular}{|l|c|c|c|}
\hline & $\begin{array}{c}\text { Branching } \\
\text { pattern }\end{array}$ & $\begin{array}{c}\text { Grid } \\
\text { pattern }\end{array}$ & $\begin{array}{c}\text { Grid } \\
\text { pattern } \\
\text { with Loop }\end{array}$ \\
\hline $\begin{array}{l}\text { Req. Pressure at } \\
\text { source }\end{array}$ & 2.5 & 1.85 & 1.61 \\
\hline $\begin{array}{l}\text { Max. velocity } \\
\text { (m/s) }\end{array}$ & 8.1 & 7.31 & 7.21 \\
\hline $\begin{array}{l}\text { Total Water } \\
\text { Required (1/min) } \\
\text { (Flow) }\end{array}$ & 2318.86 & 2091.77 & 2064.67 \\
\hline $\begin{array}{l}\text { Volume - Entire } \\
\text { System }\end{array}$ & 272.71 & 428.2 & 517.61 \\
\hline $\begin{array}{l}\text { Total length of } \\
\text { pipe (m) }\end{array}$ & 142.5 & 170.5 & 189.25 \\
\hline
\end{tabular}

\section{CONCLUSIONS AND RECOMMENDATIONS}

The results obtained are software generated based on SprinkCALC (A TYCO product).

From the above observations and studies, we can conclude that on the basis of certain properties, the three types of piping layouts and their uses can be summarized as follows:

Branching pattern type- In this type of layout, the pressure requirement is high, so the pump capacity increases. The flow i.e. water requirement is high, hence system volume is low i.e. the quantity of water flowing through the pipes will reduce. Total length of pipe (different size) required is minimum.

Grid pattern type - In this type of layout, pressure requirement is lesser than Branching pattern type, but higher than the Grid pattern with loop type piping layout.

Grid pattern with loop type- In this type of layout, pressure requirement is low, so pump capacity reduces. At the same time, system volume is high i.e. the quantity of water the pipe will increase. Recommended for areas where the source pressure is low. Central feeding of water should be used for better distribution of water (flow, pressure, etc.)

\section{ACKNOWLEDGEMENT}

I would like to thank my parents for inspiring me for such research work. Special thanks to Mr. Sushant Tambadkar for his guidance and technical support. Last but not least I would like to give sincere thanks to Mr. Hemant Khadse and team of East Corp for providing me the possible infrastructure to complete this work.

\section{REFERENCES}

[1] https://en.wikipedia.org/wiki/Hydraulic_calculation

[2] www.canutesoft.com/Table/Basic-hydraulic-calculation-for-fire-p rotection-enginee..

[3] www.ence-pumps.ru/eng/truboprovody.php

[4] www.sprinklerwarehouse.com

[5] https://media.toro.com/documents/irrigation/sprinkler-pig.pdf

[6] wiginton.net/pdf/Wiginton-Fire-Protection.pdf

[7] http://www.sfpe.org/pages/2012_Q2_3

[8] Natural gas engineering and safety challenges by G.G Nasr, N.E.Connor, p127-p145

[9] http://law.resource.org/pub/bis/is15105(2002).pdf p5- p63.

[10] http://www.nfpa.org/proposedtia998nfpa13.pdf

[11] http://www.nfpa.org/assents/files/13commDraft6-0reduced-1.pd f p17-p25, p122-126

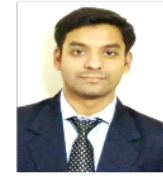

Kshitiz Vishnoi, possess a Bachelor's Degree in Mechanical Engineering from University of Mumbai. Professionally, working as a Design Engineer (MEP-Systems) in EAST-Corp, Mumbai.

INDIA

Contact No. +919869193090 